\title{
Fermentation Process and Metabolic Flux of Ethanol Production from the Detoxified Hydrolyzate of Cassava Residue
}

\begin{abstract}
Xingjiang $\mathrm{Li}^{1,2}$, Yongdong Deng ${ }^{1}$, Ying Yang ${ }^{3}$, Zhaojun Wei ${ }^{1}$, Jieshun Cheng ${ }^{1}$, Lili Cao ${ }^{1}$, Dongdong $\mathrm{Mu}^{1}$, Shuizhong $\mathrm{LuO}^{1}$, Zhi Zheng ${ }^{1,2}$, Shaotong Jiang ${ }^{1,2}$ and Xuefeng $\mathrm{Wu}^{1,2 *}$

${ }^{1}$ Department of Biological Engineering, School of Food Science and Engineering, Hefei University of Technology, Hefei, China, ${ }^{2}$ Key Laboratory for Agricultural Products Processing of Anhui Province, Hefei University of Technology, Hefei, China, ${ }^{3}$ Department of Environment Engineering, School of Environment and Energy Engineering, Anhui Jianzhu University, Hefei, China
\end{abstract}

With the growth of the world population, energy problems are becoming increasingly severe; therefore, sustainable energy sources have gained enormous importance. With respect to ethanol fuel production, biomass is gradually replacing grain as the main raw material. In this study, we explored the fermentation of five- and six-carbon sugars, the main biomass degradation products, into alcohol. We conducted mutagenic screening specifically for Candida tropicalis CICC1779 to obtain a strain that effectively used xylose (Candida tropicalis CICC1779-Dyd). By subsequently studying fermentation conditions under different initial liquid volume oxygen transfer coefficients $\left(k_{\llcorner} \alpha\right)$, and coupling control of the aeration rate and agitation speed under optimal conditions, the optimal dissolved oxygen change curve was obtained. In addition, we constructed metabolic flow charts and equations to obtain a better understanding of the fermentation mechanism and to improve the ethanol yield. In our experiment, the ethanol production of the wild type stain was $17.58 \mathrm{~g} \cdot \mathrm{L}^{-1}$ at a $k_{\mathrm{L}} \alpha$ of 120 . The highest ethanol yield of the mutagenic strains was $24.85 \mathrm{~g} \cdot \mathrm{L}^{-1}$. The ethanol yield increased to $26.56 \mathrm{~g} \cdot \mathrm{L}^{-1}$ when the dissolved oxygen content was optimized, and the conversion of sugar into alcohol reached $0.447 \mathrm{~g} \cdot \mathrm{g}^{-1}$ glucose (the theoretical titer of yeast-metabolized xylose was $0.46 \mathrm{~g}$ ethanol $/ \mathrm{g}$ xylose and the glucose ethanol fermentation titer was $0.51 \mathrm{~g}$ ethanol $/ \mathrm{g}$ glucose). Finally, the detected activity of xylose reductase and xylose dehydrogenase was higher in the mutant strain than in the original, which indicated that the mutant strain (CICC1779-Dyd) could effectively utilize xylose for metabolism.

Keywords: Candida tropicalis, fermentation, xylose, ethanol, oxygen

\section{INTRODUCTION}

With the world population growing and available land becoming scarce, energy problems are an increasing concern. Consequently, the search for alternatives to oil is a major direction of development, with ethanol derived from biomass gradually being explored by different countries (Quintero et al., 2013). For many years, grain has been the main raw material for fermented ethanol; however, reliance on grain has become a serious issue (Duque et al., 2015). In rural areas, with 
the costs of grain soaring, the production of ethanol from the fermentation of grain is becoming unsustainable leading to an urgent need for a cheap raw material replacement. In this respect, the biotransformation of cellulose is of great significance and could help to address the current worldwide energy crisis (Ebrahimi et al., 2017), grain shortages, and environmental pollution. Cellulosic and hemicellulose-rich biomass is the most promising ethanol feedstock, especially as fibrous raw materials are the richest renewable resources on Earth. The composition of cellulosic and hemicellulose-rich biomass is generally $31-40 \%$ cellulose, 35-48\% hemicellulose, and 15-25\% lignin. The use of lignocellulosic biotransformation to produce ethanol is currently a rapidly expanding area of research, and the effective use of xylose and glucose is one of the key aspects to making this biotransformation industrially viable. In other studies, sugar cane and wheat straw were both used for the production of alcohol (Dias et al., 2013; Tomas-Pejo et al., 2017). China's annual use of raw fibrous materials is about $7 \times 10^{8} \mathrm{t}$, primarily from agriculture, forestry, industry, and urban waste (Alves et al., 2015; Kang et al., 2015; Khare et al., 2015). These fibrous waste products may be used as raw materials in the production of alcohol. The main product of cellulose hydrolysis is glucose and other sixcarbon sugars, while hemicellulose hydrolyzatesare mainly xylose and other five-carbon sugars (Brienzo et al., 2009; Kamoldeen et al., 2017).

Cassava residue, a waste of lignocellulose, is the remaining solid waste after the production of tapioca starch. Its main components include starch, cellulose, hemicellulose, lignin, and a small amount of protein. It has a great recycle value and is consistent with sustainable development strategies; in particular, and it would reduce the waste of resources (Cheng et al., 2008, 2015).

Studies revealed that bacteria, filamentous fungi, and yeasts could produce alcohol by xylose fermentation. Bacteria can use several types of sugar for ethanol fermentation, but the rate is very low with the generation of many by-products. Fungi are mainly suitable for the simultaneous saccharification and fermentation of plant fiber raw materials, but the fermentation period is too long. Among those microorganisms for usage with xylose, yeast has the strongest fermentation capacity. In terms of the oxygen demand, this process can be explained by one of the two models: (1) anaerobic fermentation or (2) aerobic fermentation. Candida fits into the latter category (Mattam et al., 2016). Most studies have considered three commonly used yeast strains with pentose as a fermentation material for industrial application: Pachysolen tannophilus, Pichia stipites, and Candida tropicalis. Harinder used Candida tropicalis for ethanol production from rice straw, and the result showed that this strain could adapt to wood hydrolysate, with the yield reaching $77 \%$ of its theoretical value (Harinder et al., 2010).

Furthermore, the effects of dissolved oxygen on the fermentation of yeast have been studied. Appropriate amount of dissolved oxygen is found to be an important control parameter for ethanol fermentation; in particular, it strongly influences redox balance, cell growth, and energy generation for xylose transport (Liang et al., 2014).

If complete use of xylose from a raw fibrous material could be achieved, alcohol production could be increased by $25 \%$.
To realize the use of raw fibrous materials for the industrial production of alcohol, the effective use of both five- and sixcarbon sugars is of great importance (Galbe and Zacchi, 2012).

\section{MATERIALS AND METHODS}

\section{Screening for Mutants}

Slant medium (1 L) was prepared by dissolving glucose $(20 \mathrm{~g})$, yeast extract $(10 \mathrm{~g})$, peptone $(20 \mathrm{~g})$, and agar $(20 \mathrm{~g})$ in water. Liquid medium (1 L) was prepared by dissolving glucose $(20 \mathrm{~g})$, yeast extract $(10 \mathrm{~g})$, and peptone $(20 \mathrm{~g})$ in water. The screening medium (1 L) was prepared by dissolving xylose $(70 \mathrm{~g})$, yeast extract $(10 \mathrm{~g})$, peptone $(20 \mathrm{~g})$, and agar $(20 \mathrm{~g})$ in water. The fermentation medium ( $1 \mathrm{~L}$ ) was prepared by dissolving including glucose $(30 \mathrm{~g})$, xylose $(30 \mathrm{~g})$, ammonium sulfate $(5 \mathrm{~g})$, potassium dihydrogen phosphate $(1 \mathrm{~g})$, yeast extract $(10 \mathrm{~g})$, magnesium sulfate heptahydrate $(1 \mathrm{~g})$, and peptone $(20 \mathrm{~g})$ in water.

Candida tropicalis CICC1779 was cultured to the logarithmic growth phase, and then the yeast concentration was adjusted with physiological saline to $10^{9} \mathrm{cfu} \cdot \mathrm{mL}^{-1}$. Under the action of a magnetic stirrer, the yeast was irradiated with UV light for 20-80 s (Watanabe et al., 2011). Dilute mutated yeast solutions were coated onto a solid plate, inoculated in the xylose screening medium, and incubated at $30^{\circ} \mathrm{C}$ for 2 days. Then, selected wellgrown strains were inoculated into high concentration xylose screening medium for 1-2 days. At last, using the Dushi tube screening method, tetrazolium chloride (TTC) was used as a colorimetric method for screening yeast mutants. TTC is a colorimetric indicator, which is originally colorless but turns red in the presence of live yeast with strong dehydrogenase reduction activity. Thus, in the presence of TTC, the tiny colonies on the plate become brightly dyed with a visible red color. The color intensity is an indicator of the yeast's capacity to produce alcohol, with deep red indicating high alcohol production, followed by pink for moderate production, and colorless for little or no production (Guo et al., 2016). After screening, the strain that yielded the best alcohol production and was the most robust was chosen and named Candida tropicalis CICC1779-Dyd (deposited at Hefei University of Technology).

\section{Preparation of Seed Liquid}

Liquid medium was placed in an autoclave at $121^{\circ} \mathrm{C}$ for $20 \mathrm{~min}$ and then cooled to room temperature. The yeast was stored in a liquid medium in a test tube at $4^{\circ} \mathrm{C}$. To prepare the seed liquid, the yeast was placed on a shaker $\left(120 \mathrm{r} \cdot \mathrm{min}^{-1}, 34^{\circ} \mathrm{C}\right)$ for 13 $\mathrm{h}$, and inoculated into fresh liquid medium at $10 \%$ inoculums for $13 \mathrm{~h}$. Finally, samples were centrifuged at 7,000 $\mathrm{g}$ for 8 min. The supernatant was discarded, and the suspension was supplemented with physiological saline.

\section{Fermentation Process}

The effects of different liquid oxygen transfer coefficients $\left(k_{\mathrm{L}} \alpha\right)$ on fermentation were examined. The main factors that determine the $k_{\mathrm{L}} \alpha$ value are speed and ventilation (Garcia-Ochoa et al., 2009). The fermentation medium (7 L) was added to a $15 \mathrm{~L}$ boiling tank (Sartorius, Gottingen, Germany). The sterilization conditions were $121^{\circ} \mathrm{C}$ for $15 \mathrm{~min}$. After sterilization, samples 
were cooled to $34^{\circ} \mathrm{C}$, followed by inoculation of the yeast suspension. The fermentation temperature was set to $34^{\circ} \mathrm{C}$ and the initial $\mathrm{pH}$ was adjusted to 4.0. This experiment used a twofactor three-level central composite design (CCD; Design Expert 8.0, USA) in Table 1.

\section{Analytical Methods}

The sugar content was determined by high-performance liquid chromatography (Agilent 1260; Santa Clara, CA, USA) using an HPX-87 sugar analysis column. The mobile phase was 5 $\mathrm{mmol} \cdot \mathrm{L}^{-1} \mathrm{H}_{2} \mathrm{SO}_{4}$ with a solution flow rate of $0.6 \mathrm{~mL} \cdot \mathrm{min}^{-1}$. The column temperature was $65^{\circ} \mathrm{C}$ (Morales et al., 2015).

The ethanol content was determined by gas chromatography (Agilent $6890 \mathrm{~N}$ ) using the DB-624 column. The column temperature was $100^{\circ} \mathrm{C}$ for $1 \mathrm{~min}$ then increased at a rate of $15^{\circ} \mathrm{C} \cdot \mathrm{min}^{-1}$ to reach $190^{\circ} \mathrm{C}$, which was maintained for $3 \mathrm{~min}$. The column flow rate for high purity nitrogen was $30 \mathrm{~mL} \cdot \mathrm{min}^{-1}$ (constant current). The gas flow was comprised of hydrogen at $300 \mathrm{~mL} \cdot \mathrm{min}^{-1}$ and air at $400 \mathrm{~mL} \cdot \mathrm{min}^{-1}$. The inlet temperature was $200^{\circ} \mathrm{C}$ and the detector temperature was $250^{\circ} \mathrm{C}$ (Dong et al., 2013). The cell weight was measured by drying at a constant temperature.

\section{Determination of the Oxygen Transfer Coefficient $\left(k_{\llcorner} \alpha\right)$}

The initial volumetric oxygen transfer coefficient $\left(k_{\mathrm{L}} \alpha\right)$ was determined using the dynamic gassing-out methodology (physical method). Nitrogen was used to reduce the dissolved oxygen content to zero before fermentation, and the agitation speed and aeration rate were immediately adjusted to the same conditions used in the fermentation experiments. The dissolved oxygen concentration was measured at $5 \mathrm{~s}$ intervals throughout the aeration process using a serializable galvanic electrode (INPRO 6800 series; Mettler-Toledo, Columbus, OH, USA) connected to a Teflon-silicone-Teflon membrane. The equipment was previously calibrated at atmospheric pressure. The dissolved oxygen mass balance in the liquid phase can be expressed as follows (Fernández-Sandoval et al., 2017):

$$
\frac{\mathrm{dC}_{\mathrm{L}}}{d}=k_{\mathrm{L}} \alpha\left(\mathrm{C}^{*}-\mathrm{C}_{\mathrm{L}}\right)-\mathrm{r}_{\mathrm{o} 2}=\mathrm{OTR}-\mathrm{OUR}
$$

TABLE 1 | Central composite experimental design.

\begin{tabular}{lrrrrr}
\hline Experiments & \multicolumn{2}{c}{ Coded levels } & & \multicolumn{2}{c}{ Real levels } \\
\cline { 2 - 3 } \cline { 5 - 6 } & $\mathbf{X}_{\mathbf{1}}$ & $\mathbf{X}_{\mathbf{2}}$ & & $\mathbf{X}_{\mathbf{1}}$ (rpm) & $\mathbf{X}_{\mathbf{2}}\left(\mathbf{L} \cdot \mathbf{m i n}^{-1}\right)$ \\
\hline 1 & 1 & 1 & & 450 & 3 \\
2 & -1 & 1 & 150 & 3 \\
3 & 1 & -1 & & 450 & 1 \\
4 & -1 & -1 & & 150 & 1 \\
5 & 0 & 0 & 300 & 2 \\
6 & 0 & 0 & 300 & 2 \\
7 & 0 & 0 & 300 & 2 \\
\hline
\end{tabular}

A, Agitation speed; B, Aeration rate.
Where $C_{L}$ represents the dissolved oxygen concentration, $C^{*}$ is the saturated oxygen concentration in the liquid, and OTR is the rate of oxygen transfer. When the oxygen uptake rate (OUR) is zero, the mass balance in the oxygen liquid phase can be simplified as follows:

$$
\frac{\mathrm{dC}_{\mathrm{L}}}{d}=k_{\mathrm{L}} \alpha\left(\mathrm{C}^{*}-\mathrm{C}_{\mathrm{L}}\right)-\mathrm{r}_{\mathrm{o} 2}=\mathrm{OTR}
$$

The initial $k_{\mathrm{L}} \alpha$ value was obtained based on the straight-line slope representing the oxygen mass balance integration in the absence of microorganisms:

$$
\ln \left(1-\frac{\mathrm{C}_{\mathrm{L}}}{\mathrm{C}^{*}}\right)=-k_{L} \alpha \times \mathrm{t}
$$

\section{Metabolic Flow Analysis Method}

The metabolic flux analysis was carried out with the intention of calculating volumetric rates of formation of intracellular metabolites (Nielsen, 2001). On the basis of a pseudo-steady-state assumption for intracellular metabolites (Riascosa et al., 2005), there was no accumulation of any intermediates:

$$
r=\mathrm{G}^{\mathrm{T}} \mathrm{V}
$$

Where $r$ represents the net formation rates of metabolites $(\mathrm{mmol} / \mathrm{g} \mathrm{DW} \mathrm{h}), \mathrm{V}$ is the internal reaction rates $(\mathrm{mmol} / \mathrm{g} \mathrm{DW} \mathrm{h})$, and $G$ is the total stoichiometric matrix for all reactants and products of reactions. Finally, the metabolic flux calculation was carried out using the mathematical functions of MMULT and MINVERSE in EXCEL 2007.

\section{Data Analysis}

All values were measured in triplicate with their uncertainty within 5\%. One-way analysis of variance (ANOVA) with Duncan's new multiple range test was used $(p<0.05)$. All analyses were performed using Microsoft Office Excel 2007 and Origin 8.0 (OriginLab USA).

\section{Preparation of Hydrolyzed Sugar from Cassava Residue}

First, the appropriate amount of cassava residue was weighed and placed in a cooking pot (Dussán et al., 2014). Then, the appropriate amount of $0.8 \% \mathrm{H}_{2} \mathrm{SO}_{4}$ was added and the mixture was heated to $190^{\circ} \mathrm{C}$ in an oil bath, undergoing hydrolysis conditions for $4 \mathrm{~min}$ before removal and rapid cooling. The sample was then centrifuged to obtain a primary hydrolyzate (Souto et al., 2017). The remaining residue was placed into the cooking pot, and the appropriate amount of $1.8 \% \mathrm{H}_{2} \mathrm{SO}_{4}$ was added. The mixture was heated at $220^{\circ} \mathrm{C}$ in an oil bath for $4 \mathrm{~min}$, after which it was removed and rapidly cooled. After centrifugation, the secondary hydrolyzate was collected (Nanssou et al., 2016). The two hydrolyzate fractions were mixed. Excess calcium hydroxide was added to the hydrolyzate, mixed well, and the mixture was then centrifuged at $8,000 \mathrm{r} \cdot \mathrm{min}^{-1}$ for 10 min. The supernatant was obtained, and its $\mathrm{pH}$ was adjusted to 5.0 with dilute sulfuric acid. After this, the appropriate amount of activated carbon was added for detoxification and certain concentration of fermented sugar was obtained accordingly. 


\section{RESULTS AND DISCUSSION}

\section{Preliminary Analysis of Mutant Strains}

The basic metabolic pathway analysis of yeast was showed in Figure 1. Under aerobic conditions, yeast goes through the EMP pathway to obtain pyruvate, and from the pyruvate enters into the TCA cycle, resulting in the energy used to maintain the growth and metabolism of cells. In the absence of oxygen, pyruvic acid is converted directly to acetaldehyde, and then converted to

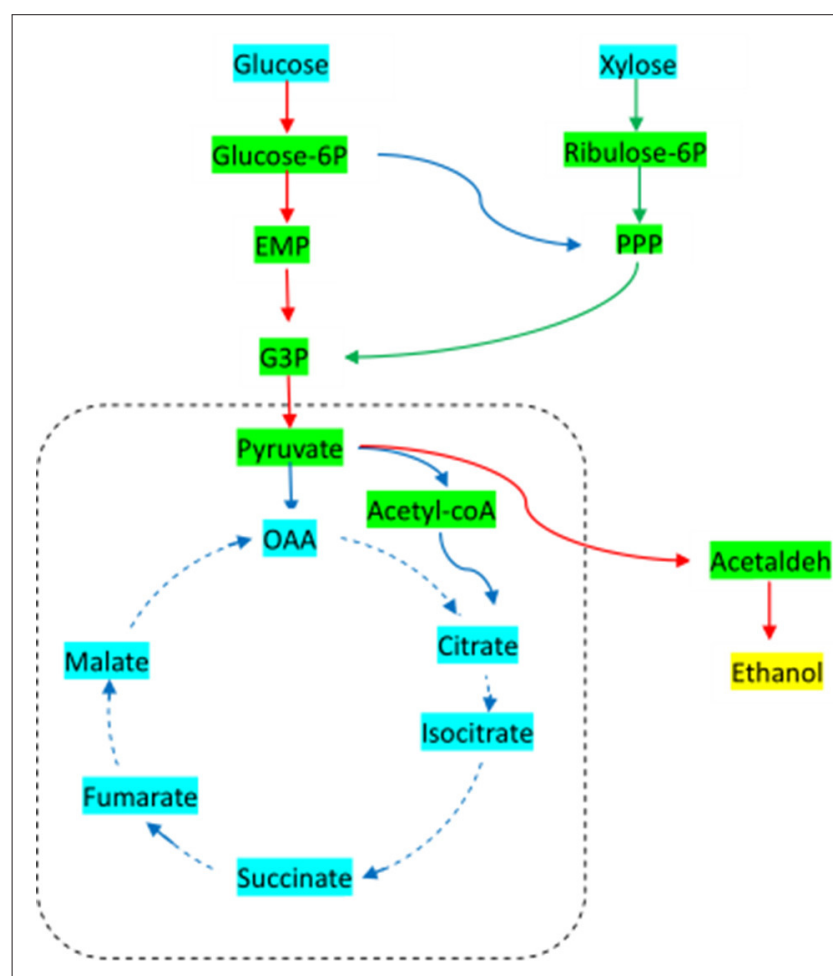

FIGURE 1 | Basic metabolic pathway for Candida tropicalis CICC1779-Dyd. EMP, embden-meyerhof-parnas pathway; PPP, pentose phosphate pathway; G3P, glyceraldehyde 3-phosphate; OAA, oxaloacetic acid.

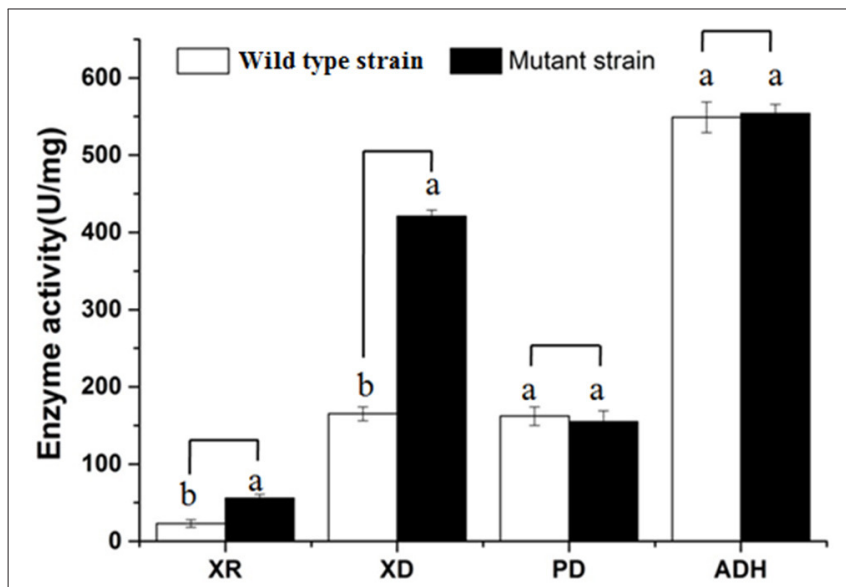

FIGURE 2 | Comparison of key enzyme activities. XR, Xylose dehydrogenase; $X D$, Xylose dehydrogenase; PD, Pyruvate decarboxylase; ADH, Alcohol dehydrogenase; $a, b$ the bars show significant differences $(P<0.05)$. ethanol, which is essentially the anaerobic respiration pathway of yeast. Xylose, on the other hand, is first transformed by xylose reductase to get xylitol, and then is converted by xylose dehydrogenase to xylulose. Finally, the products go through the phosphate pentose pathway (PPP), which is involved in the EMP pathway, in order to complete the use of five- and sixcarbon sugars. The key enzymes of these processes include xylose reductase, xylose dehydrogenase, pyruvate decarboxylase, and ethanol dehydrogenase.

As can be seen from Figure 2, the activities of several key enzymes differ between the original yeast strain and the mutant strain. We can see significant improvement in the activity of the mutant strains of xylose reductase and xylose dehydrogenase relative to the wild type stain, indicating that the existence of metabolic xylose-related enzymes leads to the effective use of xylose for metabolism, in preparation for the coupling of the PPP path with the EMP path. From the high activity of pyruvate decarboxylase and ethanol dehydrogenase, it is evident that the yeast has a strong ability to produce alcohol.

\section{Fermentation Results for Various Initial $\boldsymbol{k}_{\mathrm{L}} \alpha$ values (72 h)}

In order to investigate the fermentation potential of the mutant strain, we studied on its fermentation parameters and the results were showed in Tables 2, 3.

TABLE 2 | Test coding and fermentation results.

\begin{tabular}{lccccc}
\hline No. & \multicolumn{2}{c}{ Variables } & $\mathbf{K}_{\mathrm{L}} \alpha$ initial $\left.\mathbf{( h}^{-1}\right)$ & \multicolumn{2}{c}{ Results } \\
\cline { 2 - 3 } & $\begin{array}{c}\mathbf{X}_{\mathbf{1}} \\
(\mathbf{r p m})\end{array}$ & $\begin{array}{c}\mathbf{X}_{\mathbf{2}} \\
\left(\mathbf{L} \cdot \mathbf{m i n}^{-1}\right)\end{array}$ & & $\begin{array}{c}\text { Ethanol } \\
(\mathbf{g} / \mathbf{L})\end{array}$ & $\begin{array}{c}\text { Cell concentration } \\
(\mathbf{g} / \mathbf{L})\end{array}$ \\
\hline 1 & 450 & 3 & 145 & 21.23 & 6.12 \\
2 & 150 & 3 & 100 & 23.01 & 5.79 \\
3 & 450 & 1 & 120 & 24.85 & 6.49 \\
4 & 150 & 1 & 55 & 18.45 & 5.45 \\
5 & 300 & 2 & 85 & 22.58 & 5.87 \\
6 & 300 & 2 & 86 & 22.57 & 5.86 \\
7 & 300 & 2 & 84 & 22.56 & 5.84
\end{tabular}

TABLE 3 | Parameter estimates for fermentation results for various initial $k_{\mathrm{L}} \alpha$ values (72 h).

\begin{tabular}{|c|c|c|c|c|c|}
\hline \multirow[t]{2}{*}{ Parameters } & \multicolumn{5}{|c|}{$\mathbf{K}_{\mathrm{L}} \alpha$ initial $\left(\mathbf{h}^{-1}\right)$} \\
\hline & 55 & 85 & 100 & 120 & 145 \\
\hline $\begin{array}{l}\text { Residual concentration of glucose } \\
(\mathrm{g} / \mathrm{L})\end{array}$ & 1.35 & 1.22 & 3.56 & 2.35 & 2.98 \\
\hline $\begin{array}{l}\text { Residual concentration of xylose } \\
(\mathrm{g} / \mathrm{L})\end{array}$ & 1.32 & 1.21 & 3.21 & 2.05 & 2.58 \\
\hline Cell concentration (g/L) (g/L) & 5.45 & 5.86 & 5.79 & 6.49 & 6.12 \\
\hline Ethanol titer (g/L) & 18.45 & 22.58 & 23.01 & 24.85 & 21.23 \\
\hline Ethanol productivity $Q_{p}\left(g / L \cdot h^{-1}\right)$ & 0.256 & 0.314 & 0.320 & 0.345 & 0.296 \\
\hline Biomass yield $\mathrm{Y}_{\mathrm{X} / \mathrm{s}}(\mathrm{g} / \mathrm{g})$ & 0.095 & 0.102 & 0.109 & 0.117 & 0.112 \\
\hline Ethanol yield $Y_{p / s}(g / g)$ & 0.322 & 0.392 & 0.432 & 0.447 & 0.390 \\
\hline
\end{tabular}



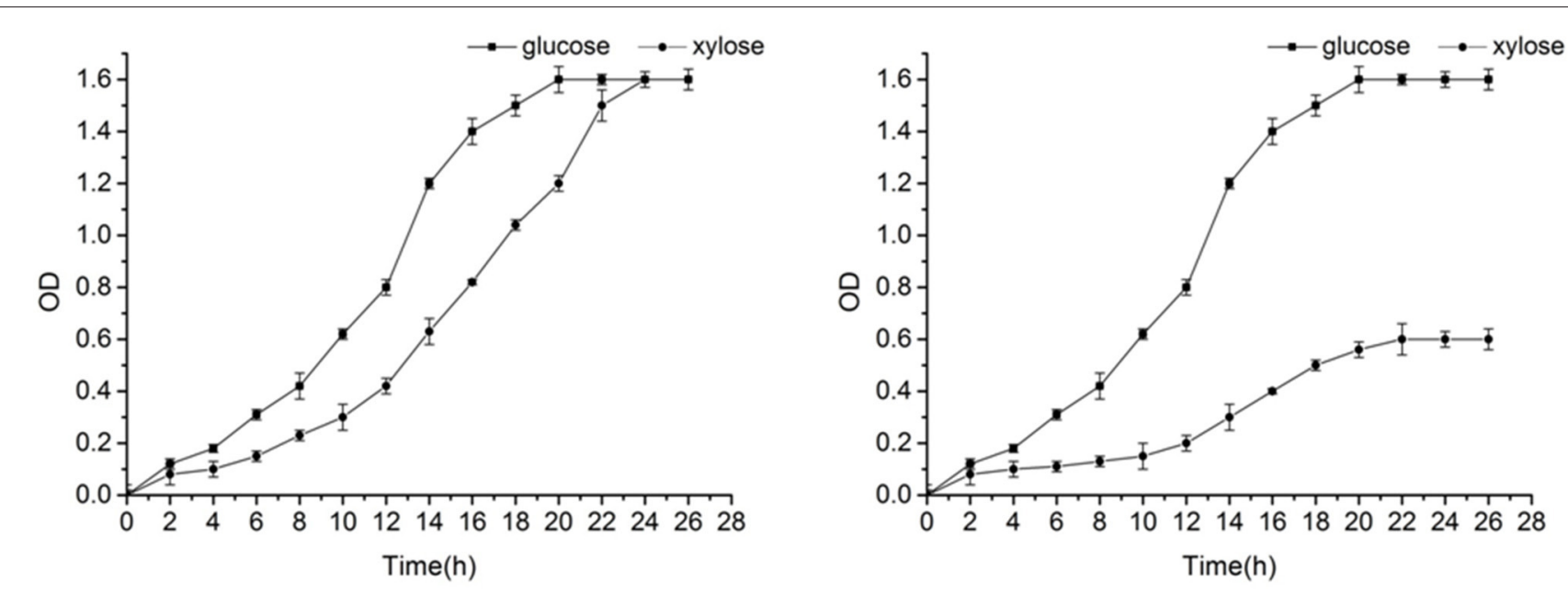

FIGURE 3 | Growth curve of Candida tropicalis CICC1779-Dyd (left) and wild type strain (right).

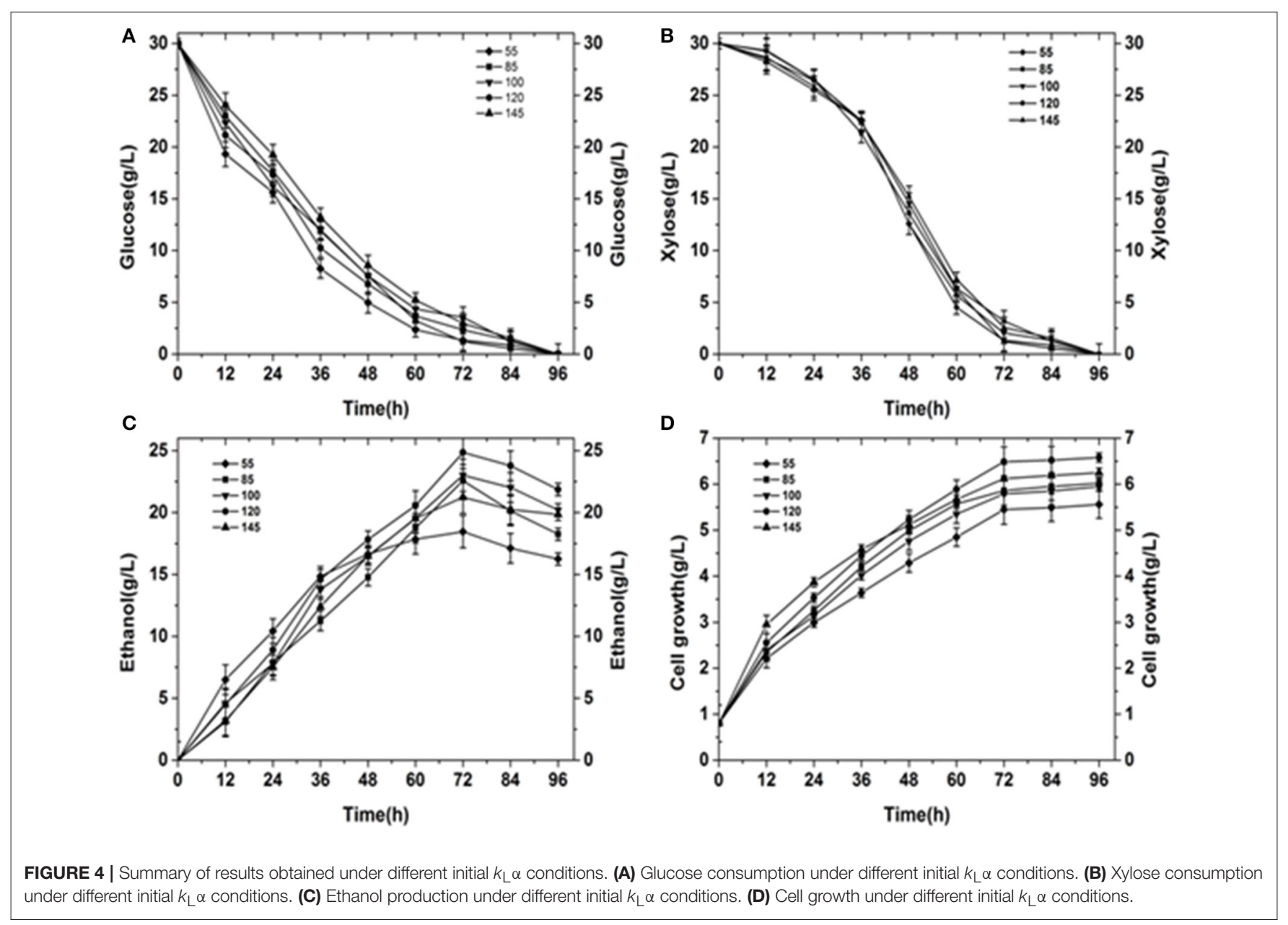

Extensive research and production practice indicates that the factors that affect the $k_{\mathrm{L}} \alpha$ value are agitation speed, aeration rate, physicochemical properties of the fermentation broth, foam state, shape of the air distributor, and the structure of the fermentor. However, we found the main factors were agitation speed and aeration rate (Table 2). The higher the agitation speed and aeration rate, the higher the $k_{\mathrm{L}} \alpha$ value. The stirrer in the fermentor maintains a uniform temperature and nutrient 


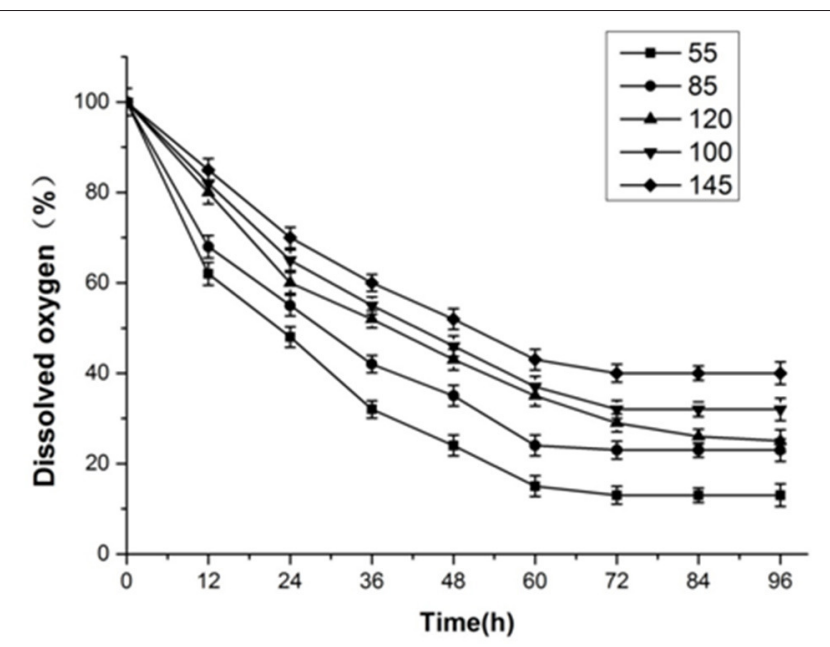

FIGURE 5 | Dissolved oxygen curve.

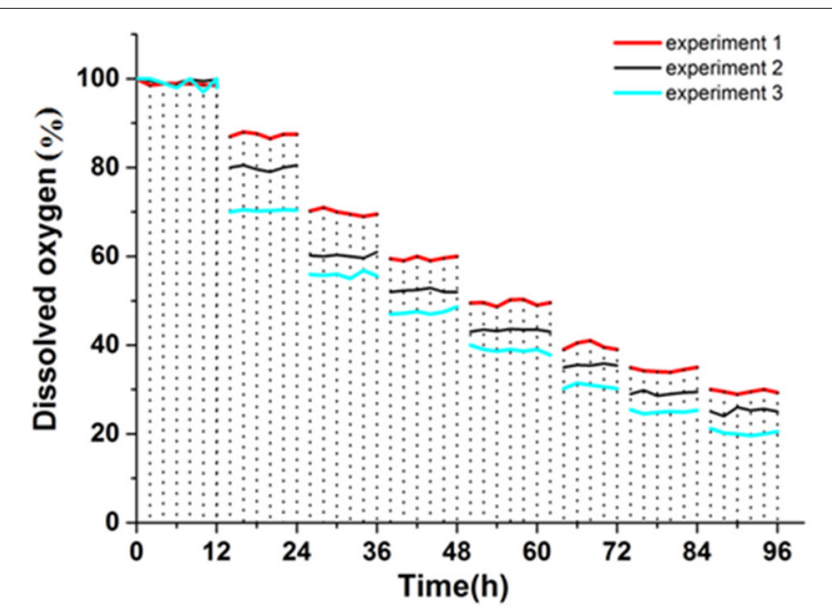

FIGURE 6 | Dissolved oxygen curve.

concentration in the fermentor, dispersing the air introduced into the fermentation broth in small bubbles to increase the gas-liquid contact area and strengthen the turbulence of the fermentation broth, thereby increasing the $k_{\mathrm{L}} \alpha$ value. An increased aeration rate will increase $k_{\mathrm{L}} \alpha$, but when it is too large, the agitator exhibits the "air pan" phenomenon, and $k_{\mathrm{L}} \alpha$ no longer increases (Kirk and Szita, 2013). An aeration rate that is too large is not conducive to the dispersion and maintenance of air in the tank, leading to a concentration of the fermentation solution, which affects the transmission of oxygen. However, when the aeration rate is too low, metabolic emissions cannot be discharged quickly, and oxygen transfer is affected.

After $72 \mathrm{~h}$ of fermentation under each condition, the parameter values for broth were summarized in Table 3. When $k_{\mathrm{L}} \alpha$ was 120 , the ethanol titer reached $24.58 \mathrm{~g} \cdot \mathrm{L}^{-1}$, the conversion of sugar into alcohol was $0.447 \mathrm{~g} \cdot \mathrm{g}^{-1}$, and the dry weight of the cells was $6.49 \mathrm{~g} \cdot \mathrm{L}^{-1}$. The lowest $k_{\mathrm{L}} \alpha$ was 55 , which gave an ethanol titer of $18.45 \mathrm{~g} \cdot \mathrm{L}^{-1}$, a sugar conversion rate of only 0.322

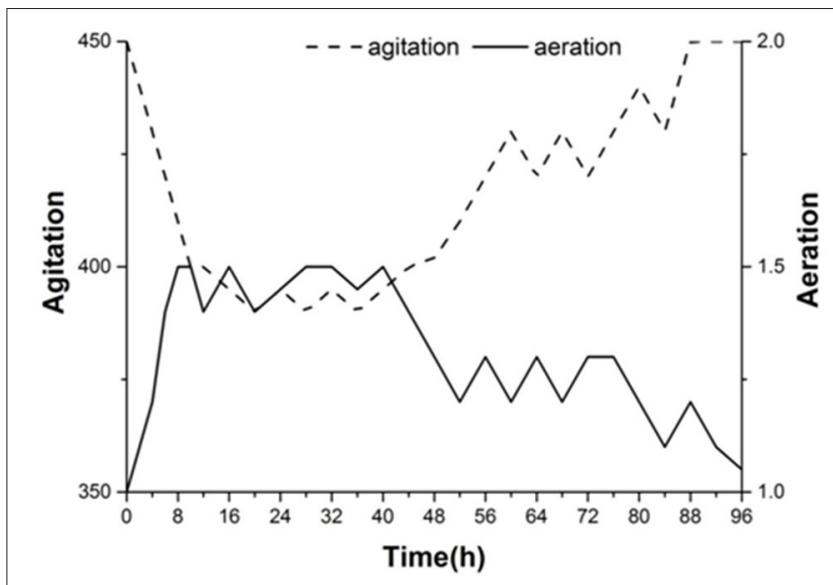

FIGURE 7 | Dissolved oxygen curve for agitation and aeration coupling conditions of the second experimental group.

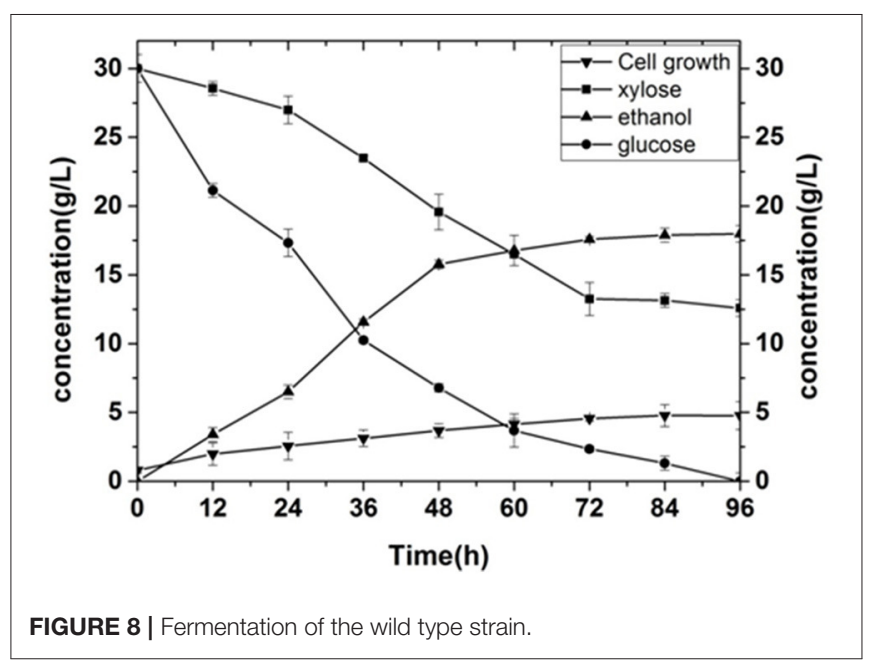

$\mathrm{g} \cdot \mathrm{g}^{-1}$, and a cell dry weight of $5.45 \mathrm{~g} \cdot \mathrm{L}^{-1}$. This indicates that $k_{\mathrm{L}} \alpha$ has a significant impact on ethanol production, and if it is too high or too low, ethanol production will be inhibited.

The yeast growth curve was showed in Figure 3, which demonstrates that the yeast can grow well in glucose and xylose. The growth curve showed a good S-shape, reaching its logarithmic growth phase, the point when cell growth is highest, at $13 \mathrm{~h}$.

The glucose consumption was showed in Figure 4A. Glucose is the most important carbon source for yeast. Glucose use was most efficient when $k_{\mathrm{L}} \alpha$ was 55 . For low $k_{\mathrm{L}} \alpha$ values, yeast cannot carry out normal aerobic metabolism, and anaerobic respiration is necessary to maintain life activity. However, the anaerobic respiration capacity is small and accordingly, large amounts of glucose must be consumed. When $k_{\mathrm{L}} \alpha$ is 145 , the sugar utilization efficiency is at its slowest. Overall, before $60 \mathrm{~h}$, glucose consumption was fast. At $60 \mathrm{~h}$, the glucose content was only $12.5-25 \%$ of the initial sugar content. At $72 \mathrm{~h}$, fermentation was close to the endpoint for $k_{\mathrm{L}} \alpha$ values of 55 and 120 . The amount of residual sugar was almost zero. However, the residual 
TABLE 4 | Metabolic reaction and related enzymes.

\begin{tabular}{|c|c|c|}
\hline No. & Enzyme & Metabolic reactions \\
\hline 1 & Glucokinase & ATP + Glucose $=A D P+$ Glucose $-6 P$ \\
\hline 2 & $\begin{array}{l}\text { Glucose-phosphate- } \\
\text { isomerase }\end{array}$ & Glucose- $6 \mathrm{P}=$ Fructose- $6 \mathrm{P}$ \\
\hline 3 & Phosphofructokinase & $\begin{array}{l}\text { ATP+Fructose- } 6 \mathrm{P}=\mathrm{ADP}+\text { Fructose }-1,6- \\
2 \mathrm{P}\end{array}$ \\
\hline 4 & $\begin{array}{l}\text { Fructose-bisphosphate- } \\
\text { aldolase }\end{array}$ & Fructose-1,6-2P=2×G3P \\
\hline 5 & Phosphoglycerate- $\mathrm{k}=$ kinase & $\begin{array}{l}\mathrm{G} 3 \mathrm{P}+\mathrm{NAD}^{+}+\mathrm{Pi}+\mathrm{ADP}=\mathrm{PEP}+\mathrm{NADH}+\mathrm{ATP} \\
+\mathrm{H}_{2} \mathrm{O}+\mathrm{H}^{+}\end{array}$ \\
\hline 6 & Xylose reductase & $\mathrm{NADPH}+$ Xylose $=$ Xylitol+NADP ${ }^{+}$ \\
\hline 7 & Xylose dehydrogenase & Xylitol+NAD ${ }^{+}=$Xylulose+NADH \\
\hline 8 & Xanthine kinase & $\begin{array}{l}\text { ATP }+ \text { Xylulose }=\text { ADP }+5 \text {-phosphate } \\
\text { xylulose }\end{array}$ \\
\hline 9 & $\begin{array}{l}\text { Glucose-6- } \\
\text { phosphatedehydro } \\
\text { genase }\end{array}$ & $\begin{array}{l}\text { Glucose- } \\
6 \mathrm{P}+2 \mathrm{NADP}^{+}=2 \mathrm{NADPH}+\text { Ribulose- } \\
5 \mathrm{P}+\mathrm{CO}_{2}\end{array}$ \\
\hline 10 & $\begin{array}{l}\text { Ribose 5-phosphate } \\
\text { isomerate }\end{array}$ & Ribulose-5P=Ribose-5P \\
\hline 11 & Transketolase & Ribose- $5 P+$ ylulose- $5 P=S e p-7 P+G 3 P$ \\
\hline 12 & Transaldolase & Sep-7P+G3P=Eyr-4P+Fructose-6P \\
\hline 13 & Transketolase & Eyr- $4 \mathrm{P}+$ Xylulose $-5 \mathrm{P}=\mathrm{G} 3 \mathrm{P}+$ Fructose $-6 \mathrm{P}$ \\
\hline 14 & $\begin{array}{l}\text { Ribulose-phosphate-3- } \\
\text { epimerate }\end{array}$ & Xylulose-5P=Ribulose-5P \\
\hline 15 & Pyruvate-kinase & $\mathrm{ADP}+\mathrm{PEP}=\mathrm{ATP}+$ Pyruvate \\
\hline 16 & Pyruvate carboxylase & $\begin{array}{l}\text { Pyruvate }+\mathrm{CoA}+\mathrm{NAD}^{+}=\text {Acetyl- } \\
\mathrm{CoA}+\mathrm{CO}_{2} \\
+\mathrm{NADH}\end{array}$ \\
\hline 17 & Pyruvate dehydrogenase & $\mathrm{ATP}+$ Pyruvate $+\mathrm{HCO}_{3}^{-}=\mathrm{ADP}+\mathrm{Pi}+\mathrm{OAA}$ \\
\hline 18 & Citrate synthase & Acetyl $-\mathrm{CoA}+\mathrm{H}_{2} \mathrm{O}+\mathrm{OAA}=$ Citrate $+\mathrm{CoA}$ \\
\hline 19 & Aconitine synthase & Citrate $=$ Isocitrate \\
\hline 20 & Isocitrate dehydrogenase & Isocitrate $+\mathrm{NAD}^{+}=\alpha-\mathrm{K}+\mathrm{CO}_{2}+\mathrm{NADH}$ \\
\hline 21 & Succinate dehydrogenase & $\mathrm{FAD}^{+}+$Fumarate $=$Succinate $+\mathrm{FADH}$ \\
\hline 22 & Fumarase & Fumarate $+\mathrm{H}_{2} \mathrm{O}=\mathrm{L}$-malic acid \\
\hline 23 & Malate dehydrogenase & Malate $+\mathrm{NAD}^{+}=\mathrm{OAA}+\mathrm{NADH}+\mathrm{H}^{+}$ \\
\hline 24 & Pyruvate decarboxylase & Pyruvate $=$ Acetaldehyde $+\mathrm{CO}_{2}$ \\
\hline 25 & Alcohol dehydrogenase & Acetaldehyde $+\mathrm{NADH}=$ Ethanol $+\mathrm{NAD}^{+}$ \\
\hline 26 & Acetyl coenzyme & $\begin{array}{l}\text { Acetaldehyde }+\mathrm{NAD}^{+}=\text {Acetic } \\
\text { acid }+\mathrm{NADH}\end{array}$ \\
\hline 27 & Aldehyde dehydrogenase & $\begin{array}{l}\text { Acetic acid }+C o A+2 A T P=A c e t y l- \\
C o A+2 A D P+2 P i\end{array}$ \\
\hline
\end{tabular}

sugar content for the remaining $k_{\mathrm{L}} \alpha$ conditions was close to $10 \%$ near the end of the fermentation period at $84 \mathrm{~h}$.

The change of xylose content was showed in Figure 4B during the fermentation process. The use of xylose is a major problem in ethanol fermentation. Wild strains utilizing xylose for ethanol fermentation are rare. Additionally, the efficiency of xylose alcohol production is typically very low. In our analysis, the rate of xylose use in the first $36 \mathrm{~h}$ was very slow. In the presence of glucose, yeast first uses glucose, before using xylose. Between 36 and $60 \mathrm{~h}$, the consumption of xylose was very fast. At this point, xylose became the main source for yeast fermentation. The rate of xylose utilization was similar for different $k_{\mathrm{L}} \alpha$ conditions. At $72 \mathrm{~h}$, near the end of the fermentation period, the amount of residual xylose sugar was less than $8 \%$ (Fernández-Sandoval et al., 2017).

Ethanol titer during the fermentation process was showed in Figure 4C. Ethanol was the target product. The maximum ethanol titer was obtained when $k_{\mathrm{L}} \alpha$ was 120 . The maximum ethanol titer achieved was $24.85 \mathrm{~g} \cdot \mathrm{L}^{-1}$, which was obtained at 72 $\mathrm{h}$. The conversion rate of sugar to alcohol was $0.447 \mathrm{~g} \cdot \mathrm{g}^{-1}$ (the theoretical titer of yeast-metabolized xylose was $0.46 \mathrm{~g}$ ethanol/g xylose while the ethanol titer for glucose fermentation was $0.51 \mathrm{~g}$ ethanol/g glucose; (Ranganathan et al., 2017). The lowest ethanol titer was $18.45 \mathrm{~g} \cdot \mathrm{L}^{-1}$ at a $k_{\mathrm{L}} \alpha$ of $55(72 \mathrm{~h})$. For a lower agitation speed and aeration rate, yeast growth was poor and alcohol production was low. However, irrespective of the initial $k_{\mathrm{L}} \alpha$ conditions, final fermentation ended near $72 \mathrm{~h}$. After $72 \mathrm{~h}$, the ethanol content decreased because the yeast required energy to maintain growth. The amount of residual sugar was almost zero, so all of the yeast consumed some ethanol to obtain energy.

Cell weight curve during the process of fermentation was showed in Figure 4D. Cell growth was fastest for a $k_{\mathrm{L}} \alpha$ of 120 and slowest for a $k_{\mathrm{L}} \alpha$ of 55. Although the rate of cell growth was different for different $k_{\mathrm{L}} \alpha$ values, the rate of growth in the first $12 \mathrm{~h}$ was significantly higher than that after $12 \mathrm{~h}$, because at 12 $\mathrm{h}$ the yeast was in the logarithmic growth phase. The maximum cell weight was $6.49 \mathrm{~g} \cdot \mathrm{L}^{-1}$ for an initial $k_{\mathrm{L}} \alpha$ of 120 , and this was significantly higher than the maximum cell weight under other $k_{\mathrm{L}} \alpha$ conditions.

\section{Dissolved Oxygen Analysis}

In the case of different initial $k_{\mathrm{L}} \alpha$ values, the initial dissolved oxygen amount was set to $100 \%$. We then followed the change of dissolved oxygen over time for different values of $k_{\mathrm{L}} \alpha$.

It can be seen from Figure 5 that the amount of dissolved oxygen clearly declined in the first $60 \mathrm{~h}$, and later stabilized. The amount of dissolved oxygen is important for the fermentation of yeast, directly affecting the fermentation stability, and is an important parameter of fermentation control. Aerobic respiration occurs with appropriate amounts of dissolved oxygen, allowing the yeast to produce more energy that accelerates growth and metabolism. Below the critical amount of dissolved oxygen, anaerobic respiration (fermentation) occurs, resulting in ethanol and other metabolites. With a large number of yeast breeding, oxygen demand grows and the dissolved oxygen concentration in the tank decreases. Since the fermentation condition is best when $k_{\mathrm{L}} \alpha$ is 120 , a set of experimental results was obtained by simulating the change in dissolved oxygen by controlling the agitation and aeration coupling.

Figure 6 showed that three sets of experimental values were obtained by three sets of simulation experiments. The first group of experimental ethanol production was $22.56 \mathrm{~g} \cdot \mathrm{L}^{-1}(72 \mathrm{~h})$, the second group was $26.56 \mathrm{~g} \cdot \mathrm{L}^{-1}(72 \mathrm{~h})$, and the third group was $23.85 \mathrm{~g} \cdot \mathrm{L}^{-1}(72 \mathrm{~h})$.

Figure 7 shows the agitation and aeration coupling curve for the second group of experiments. To control the amount of dissolved oxygen at different stages of the fermentation process, we used the coupling of agitation and aeration to adjust the oxygen content. We can see that increased aeration and decreased agitation helps increase the dissolved oxygen in 


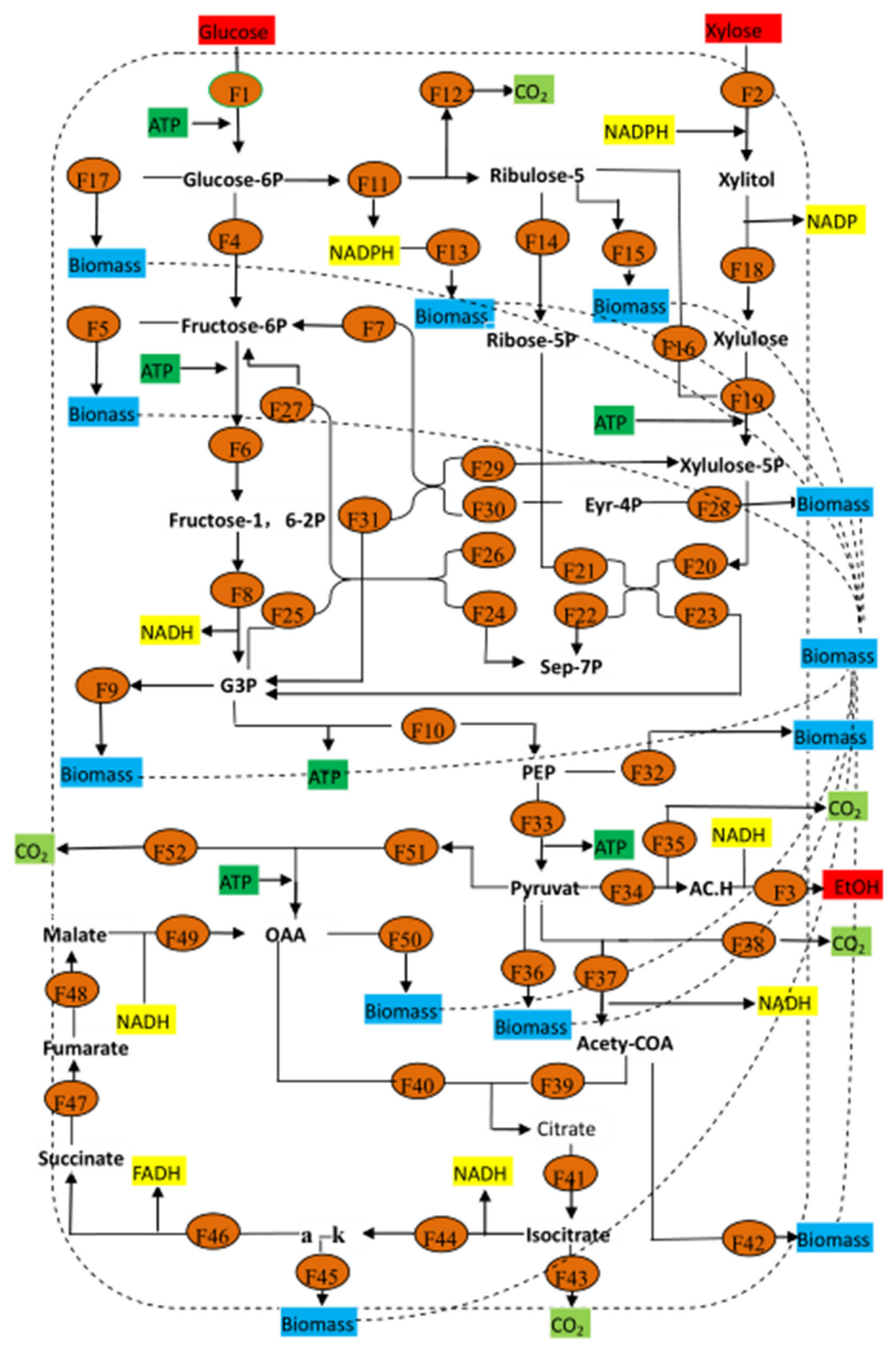

FIGURE 9 | Metabolic flux for Candida tropicalis CICC1779-Dyd. All the word Biomasshere refers to the biological composition on the cell. Glucose-6P, 6-phosphate dextrose; Fructose-6P, fructose 6 phosphate; Fructose-1, 6-2P Fructose-1, 6-2 phosphate; Ribulose-5, 5 phosphate ribuolse; Ribulose-5P, 5 phosphate ribose; Eyr-4P, 4 phosphate erythritol; Sep-7P, 7 phosphate Jing Tian heptanose sugar; G3P, glyceraldehyde 3-phosphate; PEP, phosphoenolpyruvate; a-k, $\alpha$-keto-glutaric acid; AC.H, Acetaldehyde; Etoh, ethanol. 
the early stage, which was beneficial for yeast growth. With the decline in dissolved oxygen in the medium, aeration was gradually decreased to $1.5 \mathrm{~L} \cdot \mathrm{min}^{-1}$, and the agitation rate was increased slowly. The agitation rate increased by nearly 450 $\mathrm{r} \cdot \mathrm{min}^{-1}$ and aeration was reduced to $1.0 \mathrm{~L} \cdot \mathrm{min}^{-1}$ in the later stage of fermentation. During this period, it was beneficial to decrease the viscosity of the fermentation broth and increase the fermentation.

\section{Comparative Fermentation Analysis of Wild Type Strain and Mutant Strain $(k\llcorner\alpha=120)$}

In order to compare the productivity of the mutant with that of the wild type strain, we analyzed the main parameters, and Figure 8 showed the fermentation of the original yeast strain at a $k_{\mathrm{L}} \alpha$ of 120 . For the wild type stain, glucose utilization was better with a utilization rate of nearly $95 \%$, but the use of xylose was poor. The residual sugar content of xylose was close to 13.25 $\mathrm{g} \cdot \mathrm{L}^{-1}$ after $72 \mathrm{~h}$ of fermentation, and the utilization rate of xylose only reached $55.8 \%$. This resulted in an ethanol production of only $17.58 \mathrm{~g} \cdot \mathrm{L}^{-1}$. However, the ethanol production of mutagenic screened yeast at a $k_{\mathrm{L}} \alpha$ of 120 was $24.85 \mathrm{~g} \cdot \mathrm{L}^{-1}$, with a utilization rate of glucose of $92 \%$, and a utilization rate of xylose of $91 \%$. These results indicate that the mutant yeast strain exhibits greatly improved xylose consumption compared to the wild type stain.

\section{Metabolic Flux Analysis}

After studying the effects of different fermentation processes on ethanol production, metabolic reaction and related enzymes were analyzed in Table 4, the metabolic flow chart was constructed and the metabolic equations were listed. The flow rate of each metabolic point was calculated using the matrix and subsequently analyzed. In order to clarify metabolism of the strains, we analyzed the metabolic pathway and its flux.

Figure 9 shows the metabolic flow chart of yeast, and Tables 5, 6 list 53 flow equations and their flow values. While equations 1-39 are based on the bioreactivity of the mass balance of the base material, the coefficient constants of equations 39-50 are based on past studies (Longacre et al., 1997; McKinlay et al., 2007). Substrate input, product output, and cell production were directly detected. The cell biomass was nearly fixed in the range of 60-72 h, and consequently we chose this period for our flux analysis. The total throughput of the system had 53 metabolites corresponding to 53 responses, which were calculated by the matrix of these fluxes, the results of which are shown Table 6.

Changes in input substrate and product flux were consistent with changes in glucose and xylose consumption as well as ethanol production. Table 6 shows the metabolic flux data at certain condition of the wild type stain and the mutant strain. It is clear that the metabolic flux of the wild type stain is less than in other conditions, especially for the metabolism of xylose. The mutagenic strain's ability to metabolize xylose was significantly enhanced. By analyzing the influence of dissolved oxygen on the metabolic flux, it was found that increased aeration and decreased agitation in the early stage was beneficial for increasing the dissolved oxygen concentration in the tank. The respiratory metabolism of the yeast produced a lot of energy for self-growth,
TABLE 5 | Flux equations for the Candida tropicalis DYD-007.

\begin{tabular}{|c|c|c|}
\hline No. & Metabolic & Flux equations \\
\hline 1 & Glucose-6P & $\begin{array}{l}1 F_{1}-F_{4}-F_{17}-F_{11}=0 \\
2 F_{11}-F_{12}=0\end{array}$ \\
\hline 2 & Fructose & $3 \mathrm{~F}_{4}+\mathrm{F}_{7}+\mathrm{F}_{27}-\mathrm{F}_{5}-\mathrm{F}_{6}=0$ \\
\hline 3 & Fructose-1,6-2P & $4 F_{6}-0.5 \times F_{8}=0$ \\
\hline 4 & G3P & $5 F_{8}+F_{23}+F_{31}-F_{9}-F_{10}-F_{25}=0$ \\
\hline 5 & Xylitol & $6 F_{2}-F_{18}=0$ \\
\hline 6 & Xylulose & $7 F_{18}-F_{19}=0$ \\
\hline 7 & Xylulose-5P & $8 F_{16}-F_{19}+F_{20}+F_{29}=0$ \\
\hline 8 & Ribose-5P & $\begin{array}{l}9 F_{14}-F_{21}=0 \\
10 F_{22}-F_{24}=0\end{array}$ \\
\hline 9 & Sep-7P and Eyr-4P & $\begin{array}{l}11 F_{26}-F_{28}-F_{30}=0 \\
12 F_{20}-F_{21}=0 \\
13 F_{22}-F_{23}=0 \\
14 F_{20}-F_{23}=0 \\
15 F_{24}-F_{25}=0 \\
16 F_{26}-F_{27}=0 \\
17 F_{24}-F_{26}=0 \\
18 F_{29}-F_{30}=0 \\
19 F_{7}-F_{31}=0 \\
20 F_{30}-F_{31}=0\end{array}$ \\
\hline 10 & Ribulose-5P & $21 F_{11}-F_{16}-F_{14}-F_{15}=0$ \\
\hline 11 & PEP & $22 F_{10}-F_{32}-F_{33}=0$ \\
\hline 12 & Pyruvate & $\begin{array}{l}23 F_{33}-F_{34}-F_{36}-F_{37}-F_{51}=0 \\
24 F_{37}-F_{38}=0\end{array}$ \\
\hline 13 & OAA & $\begin{array}{l}25 F_{49}+F_{51}-F_{50}-F_{40}=0 \\
26 F_{51}-F_{49}=0 \\
27 F_{51}-F_{52}=0\end{array}$ \\
\hline 14 & Acetyl-CoA & $28 F_{37}-F_{39}-F_{42}=0$ \\
\hline 15 & Citrate & $\begin{array}{l}29 F_{39}+F_{40}-F_{41}=0 \\
30 F_{39}-F_{40}=0\end{array}$ \\
\hline 16 & Isocitrate & $\begin{array}{l}31 F_{41}-F_{44}=0 \\
32 F_{43}-F_{44}=0\end{array}$ \\
\hline 17 & $\alpha-k$ & $33 F_{44}-F_{45}-F_{46}=0$ \\
\hline 18 & Succinate & $34 F_{46}-F_{47}=0$ \\
\hline 19 & Fumarate & $35 \mathrm{~F}_{47}-\mathrm{F}_{48}=0$ \\
\hline 20 & Malate & $36 \mathrm{~F}_{48}-\mathrm{F}_{49}=0$ \\
\hline 21 & $\mathrm{NADPH}$ & $37 F_{2}-2 \times F_{11}=0$ \\
\hline 22 & Ethanol & $\begin{array}{l}38 F_{34}-F_{35}-F_{3}=0 \\
39 F_{35}-F_{3}=0\end{array}$ \\
\hline 25 & BM synthesis & $\begin{array}{l}40320.02 \times F_{5}=\Delta B M \\
4127.45 \times F_{9}=\Delta B M \\
423.00 \times F_{13}=\Delta B M \\
4358.78 \times F_{15}=\Delta B M \\
4498.35 \times F_{17}=\Delta B M \\
45165.26 \times F_{28}=\Delta B M \\
4676.37 \times F_{32}=\Delta B M \\
4714.59 \times F_{38}=\Delta B M \\
4826.85 \times F_{52}=\Delta B M \\
4913.41 \times F_{41}=\Delta B M \\
50134.41 \times F_{47}=\Delta B M\end{array}$ \\
\hline 26 & Substrate uptake & $51 \mathrm{~F}_{2}=\Delta$ Xylose \\
\hline 27 & Product output & $52 \mathrm{~F}_{3}=\Delta$ Ethanol \\
\hline 28 & Biomsass & $53 F_{53}=\Delta$ Biomsass \\
\hline
\end{tabular}


TABLE 6 | Results of MFA.

\begin{tabular}{|c|c|c|c|c|c|c|c|c|c|c|c|}
\hline Flux data & $\mathbf{a}$ & b & c & d & e & Flux data & $\mathbf{a}$ & b & c & d & e \\
\hline $\mathrm{F}_{1}$ & 0.698 & 1.199 & 1.299 & 0.819 & 1.119 & $F_{28}$ & 0.003 & 0.004 & 0.004 & 0.003 & 0.004 \\
\hline F2 & 0.225 & 0.035 & 0.021 & 0.062 & 0.034 & $F_{29}$ & 0.192 & 0.131 & 0.128 & 0.111 & 0.124 \\
\hline $\mathrm{F}_{3}$ & 0.973 & 1.376 & 1.471 & 0.972 & 1.287 & $\mathrm{~F}_{30}$ & 0.192 & 0.131 & 0.128 & 0.111 & 0.124 \\
\hline $\mathrm{F}_{4}$ & 0.581 & 1.174 & 1.281 & 0.783 & 1.096 & $F_{31}$ & 0.192 & 0.131 & 0.128 & 0.111 & 0.124 \\
\hline $\mathrm{F}_{5}$ & 0.002 & 0.002 & 0.002 & 0.001 & 0.002 & $F_{32}$ & 0.061 & 0.087 & 0.090 & 0.062 & 0.082 \\
\hline$F_{6}$ & 0.967 & 1.438 & 1.538 & 1.007 & 1.345 & $F_{33}$ & 2.047 & 2.895 & 3.089 & 2.046 & 2.709 \\
\hline $\mathrm{F}_{7}$ & 0.192 & 0.131 & 0.128 & 0.111 & 0.124 & $\mathrm{~F}_{34}$ & 1.947 & 2.752 & 2.941 & 1.945 & 2.574 \\
\hline$F_{8}$ & 1.934 & 2.876 & 3.0767 & 2.013 & 2.690 & $F_{35}$ & 0.973 & 1.376 & 1.471 & 0.972 & 1.287 \\
\hline $\mathrm{F}_{9}$ & 0.017 & 0.024 & 0.025 & 0.017 & 0.023 & $F_{36}$ & 0.032 & 0.046 & 0.047 & 0.032 & 0.043 \\
\hline$F_{10}$ & 2.109 & 2.982 & 3.179 & 2.107 & 2.791 & $F_{37}$ & 0.048 & 0.068 & 0.070 & 0.048 & 0.064 \\
\hline $\mathrm{F}_{11}$ & 0.113 & 0.017 & 0.011 & 0.031 & 0.017 & $\mathrm{~F}_{38}$ & 0.048 & 0.068 & 0.070 & 0.048 & 0.064 \\
\hline $\mathrm{F}_{12}$ & 0.113 & 0.017 & 0.011 & 0.031 & 0.017 & $F_{39}$ & 0.012 & 0.017 & 0.018 & 0.012 & 0.016 \\
\hline $\mathrm{F}_{13}$ & 0.156 & 0.222 & 0.230 & 0.157 & 0.210 & $\mathrm{~F}_{40}$ & 0.012 & 0.017 & 0.018 & 0.012 & 0.016 \\
\hline $\mathrm{F}_{14}$ & 0.195 & 0.135 & 0.132 & 0.114 & 0.128 & $\mathrm{~F}_{41}$ & 0.024 & 0.035 & 0.036 & 0.024 & 0.033 \\
\hline $\mathrm{F}_{15}$ & 0.080 & 0.113 & 0.117 & 0.080 & 0.107 & $\mathrm{~F}_{42}$ & 0.035 & 0.050 & 0.052 & 0.036 & 0.048 \\
\hline $\mathrm{F}_{16}$ & 0.162 & 0.231 & 0.238 & 0.163 & 0.218 & $\mathrm{~F}_{43}$ & 0.024 & 0.035 & 0.036 & 0.024 & 0.033 \\
\hline $\mathrm{F}_{17}$ & 0.005 & 0.007 & 0.007 & 0.005 & 0.006 & $\mathrm{~F}_{44}$ & 0.024 & 0.035 & 0.036 & 0.024 & 0.033 \\
\hline$F_{18}$ & 0.225 & 0.035 & 0.021 & 0.062 & 0.034 & $\mathrm{~F}_{45}$ & 0.004 & 0.005 & 0.005 & 0.003 & 0.005 \\
\hline $\mathrm{F}_{19}$ & 0.225 & 0.035 & 0.021 & 0.062 & 0.034 & $\mathrm{~F}_{46}$ & 0.021 & 0.03 & 0.031 & 0.021 & 0.028 \\
\hline $\mathrm{F}_{20}$ & 0.195 & 0.135 & 0.132 & 0.114 & 0.128 & $\mathrm{~F}_{47}$ & 0.021 & 0.03 & 0.031 & 0.021 & 0.028 \\
\hline $\mathrm{F}_{21}$ & 0.195 & 0.135 & 0.132 & 0.114 & 0.128 & $\mathrm{~F}_{48}$ & 0.021 & 0.03 & 0.031 & 0.021 & 0.028 \\
\hline $\mathrm{F}_{22}$ & 0.195 & 0.135 & 0.132 & 0.114 & 0.128 & $F_{49}$ & 0.021 & 0.03 & 0.031 & 0.021 & 0.028 \\
\hline $\mathrm{F}_{23}$ & 0.195 & 0.135 & 0.132 & 0.114 & 0.128 & $F_{50}$ & 0.017 & 0.025 & 0.026 & 0.018 & 0.023 \\
\hline $\mathrm{F}_{24}$ & 0.195 & 0.135 & 0.132 & 0.114 & 0.128 & $F_{51}$ & 0.021 & 0.03 & 0.031 & 0.021 & 0.028 \\
\hline $\mathrm{F}_{25}$ & 0.195 & 0.135 & 0.132 & 0.114 & 0.128 & $F_{52}$ & 0.021 & 0.03 & 0.031 & 0.021 & 0.028 \\
\hline$F_{26}$ & 0.195 & 0.135 & 0.132 & 0.114 & 0.128 & $F_{53}$ & 0.469 & 0.667 & 0.689 & 0.471 & 0.629 \\
\hline $\mathrm{F}_{27}$ & 0.195 & 0.135 & 0.132 & 0.114 & 0.128 & & & & & & \\
\hline
\end{tabular}

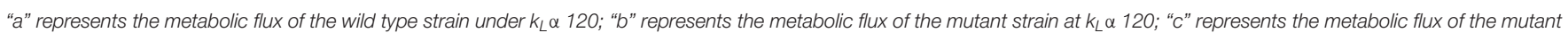

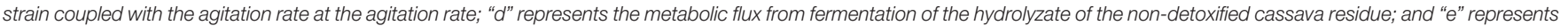

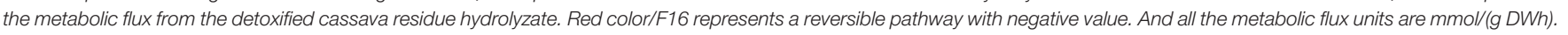

which was greater than the cell oxygen demand. This made conditions suitable for the respiratory metabolism of yeast to produce significant energy for its own breeding. When dissolved oxygen is greater than the cell oxygen demand, yeast undergoes aerobic respiration and metabolic materials cycle more from pyruvate into the tricarboxylic acid cycle to produce a large amount of energy that is used to maintain cell growth. Increasing agitation and decreasing the aeration rate is beneficial in the late stages. Air entering the fermentation broth is dispersed in small bubbles to increase the gas-liquid contact area and strengthen the turbulence of the fermentation broth, reducing the mycelia knot. During this period, the amount of dissolved oxygen is less than the cell oxygen demand, and the yeast undergoes anaerobic respiration, where the material circulates more through pyruvate and acetaldehyde metabolism to yield ethanol.

\section{Fermentation of Hydrolyzed Sugar from Cassava Residue}

The highest final yield of ethanol reached was $24.85 \mathrm{~g} \cdot \mathrm{L}^{-1}$ at $72 \mathrm{~h}$ when $k_{\mathrm{L}} \alpha$ was 120 . Based on this, we further used cassava residue hydrolyzate for fermentation.
The final concentration of glucose $34.25 \mathrm{~g} \cdot \mathrm{L}^{-1}$, xylose 25.20 $\mathrm{g} \cdot \mathrm{L}^{-1}$ were obtained from hydrolyzate from cassava residue. The ventilation and stirring rate were adjusted, so that the initial $k_{\mathrm{L}} \alpha$ was 120 . After $72 \mathrm{~h}$ of fermentation an ethanol concentration of $23.24 \mathrm{~g} \cdot \mathrm{L}^{-1}$ was obtained from the detoxified hydrolyzate and its flux was also considerably high, which is 1.287 $\mathrm{mmol} /(\mathrm{g} \mathrm{DWh})$ in Table 6. For the non-detoxified hydrolyzate, the final ethanol concentration obtained was $17.56 \mathrm{~g} \cdot \mathrm{L}^{-1}$. Detoxification was necessary as the cassava residue hydrolyzate contains cyanide and acidic substances, which will inhibit the growth and reproduction of yeast, thus affecting the ethanol yield.

\section{CONCLUSIONS}

A yeast strain was screened by UV mutagenesis, and fermentation was subsequently carried out under different initial liquid phase oxygen transfer coefficients $\left(k_{\mathrm{L}} \alpha\right)$. Compared to the wild type stain, the mutant yeast exhibited improved xylose metabolism. The experimental results show that the fermentation efficiency is highest when $k_{\mathrm{L}} \alpha$ is 120 , leading 
to an ethanol yield of $24.85 \mathrm{~g} \cdot \mathrm{L}^{-1}$ after $72 \mathrm{~h}$, which is higher than the original yeast strain, reflecting the efficient use of xylose. After optimizing the conditions of the coupled control of aeration rate and agitation speed to obtain the desired change in dissolved oxygen, ethanol production reached $26.56 \mathrm{~g} \cdot \mathrm{L}^{-1}$. Through the detection of enzyme activity, a metabolic flow chart and equations were constructed. The analysis of metabolic flux shows that dissolved oxygen has a great impact on fermentation. Thus, through these studies we have a better understanding of the metabolic mechanism of yeast and fermentation conditions, laying the foundation for the industrialization of large quantities of ethanol production.

\section{REFERENCES}

Alves, M., Ponce, G. H. S. F., and Silva, M. A. A. V. (2015). Ensinas Surplus electricity production in sugarcane mills using residual bagasse and straw as fuel. Energy 91, 751-775. doi: 10.1016/j.energy.2015.08.101

Brienzo, M., Siqueira, A. F., and Milagres, A. M. F. (2009). Search for optimum conditions of ugarcane bagasse hemicellulose extraction. Biochem. Eng. J. 46, 99-204. doi: 10.1016/j.bej.2009.05.012

Cheng, J., Lin, R., Ding, L., Song, W., Li, Y., Zhou, J., et al. (2015). Fermentative hydrogen and methane cogeneration from cassava residues: effect of pretreatment on structural characterization and fermentation performance. Bioresour. Technol. 179, 407-413. doi: 10.1016/j.biortech.2014.12.050

Cheng, K.-K., Cai, B.-Y., Zhang, J.-A., Ling, H.-Z., Zhou, Y.-J., Ge, J.-P., et al. (2008). Sugarcane bagasse hemicellulose hydrolysate for ethanol production by acid recovery process. Biochem. Eng. J. 38, 105-109. doi: 10.1016/j.bej.2007.07.012

Dias, M. O. S., Junqueira, T. L., Cavalett, O., Pavanello, L. G., Cunha, M. P., Jesus, C. D., et al. (2013). Bonomi Biorefineries for the production of first and second generation ethanol and electricity from sugarcane. Appl. Energy 109, 72-78. doi: 10.1016/j.apenergy.2013.03.081

Dong, B. Y., Chen, Y. F., Zhao, C. C., Zhang, S. J., Guo, X. W., and Xiao, D. G. (2013). Simultaneous determination of furfural, acetic acid, and 5-Hydroxymethylfur -fural in corncob hydrolysates using liquid chromatogra -phy with ultraviolet detection. J. AOAC Int. 96, 1239-1244. doi: 10.5740/jaoacint.12-290

Duque, S. H., Cardona, C. A., and Moncada, J. (2015). Techno-Economic and envir -onmental analysis of ethanol production from 10 agroindustrial residues in Colombia. Energy Fuels 29, 775-783. doi: 10.1021/ef5019274

Dussán, K. J., Silva, D. D. V., Moraes, E. D. J. C., Arruda, P. V. M. D. and Felipe, G. D. A. (2014). Dilute-acid hydrolysis of cellulose to glucose from sugarcane bagasse. Chem. Eng. Trans. 38, 433-438. doi: 10.3303/CET14 38073

Ebrahimi, M., Caparanga, A. R., Ordono, E. E., Villaflores, O. B., and Pouriman, M. (2017). Effect of ammonium carbonate pretreatment on the enzymatic digestibility, structural characteristics of rice husk and bioethanol production via simultaneous saccharification and fermentation process with Saccharomyces cerevisiae Hansen 2055. Ind. Crops Prod. 101, 84-91. doi: 10.1016/j.indcrop.2017.03.006

Fernández-Sandoval, M. T., Galíndez-Mayer, J., Moss-Acosta, C. L., Gosseta, G., and Martineza, A. (2017). Volumetric oxygen transfer coefficient as a means of improving volumetric ethanol productivity and a criterion for scaling up ethanol production with Escherichia coli. J. Chem. Technol. Biotechnol. 92, 981-989. doi: 10.1002/jctb.5087

Galbe, M., and Zacchi, G. (2012). Pretreatment The key to efficient utilization of lignocellulosic materials. Biomass Bioenergy 46, 70-78. doi: 10.1016/j.biombio-e.2012.03.026

Garcia-Ochoa, F., and Gomez, E. (2009). Bioreactor scale-up and oxygen transfer rate in microbial processes: an overview. Biotechnol. Adv. 27, 153-176. doi: 10.1016/j.biotechadv.2008.10.006

\section{AUTHOR CONTRIBUTIONS}

$\mathrm{XL}$ designed the study and wrote the protocol. YD conducted all experiments. YY, ZW, and JC took part in materials preparation. LC, DM, and SL took part in experiments. ZZ and SJ analyzed data. XW wrote and revised the manuscript.

\section{FUNDING}

This study was supported by the Science and Technology Plan Projects of Anhui Province (Grant No: 15CZZ03100, 15CZZ03096, KJ2015ZD12) and the National Natural Science Foundation of China (Grant No: 31601465).

Guo, J., Li, J. X., and Chen, Y. F. (2016). Improving Erythritol Production of Aureobasidium pullulans from Xylose by Mutagenesis and Medium Optimization. Appl. Biochem. Biotechnol. 180, 717-727. doi: 10.1007/s12010-016-2127-3

Harinder, S. O., Praveen, V. V., Khushal, B., Vinod, K. B., and Ramabhau, T. P. (2010). Enhanced ethanol production via fermentation of rice straw with hydrolysate -adapted Candida tropicalis ATCC 13803. Process Biochem. 45, 1299-1306. doi: 10.1016/j.procbio.2010.04.017

Kamoldeen, A. A., Lee, C. K., Abdullah, W. N. W., and Leh, C. P. (2017). Enhanced ethanol production from mild alkali-treated oil-palm empty fruit bunches via co-fermentation of glucose and xylose. Renewable Energy 107, 113-123. doi: 10.1016/j.renene.20-17.01.039

Kang, K. E., Chung, D., Kim, Y. B., and Chung, G. (2015). Choi High-titer ethanol production from simultaneous saccharification and fermentation using a continuous feeding system. Fuel 145, 18-24. doi: 10.1016/j.fuel.2014.12.052

Khare, S. N., Pandey, A., and Larroche, C. (2015). Current perspectives in enzymatic saccharification of lignocellulosic. Biochem. Eng. J. 102, 38-44. doi: 10.1016/j.bej.2015.02.033

Kirk, T. V., and Szita, N. (2013). Oxygen transfer characteristics of miniaturized bioreactor systems. Biotechnol. Bioeng. 110, 1005-1019. doi: 10.1002/bit.24824

Liang, M., Damiani, A., He, Q. P., and Wang, J. (2014). Elucidating xylose metabolism of Scheffersomyces stipitis for lignocellulosic ethanol production. ACS Sustainable Chem. Eng. 2, 38-48. doi: 10.1021/sc400265

Longacre, A., Reimers, J. M., Gannon, J. E., and Wright, B. E. (1997). Flux analysis of glucose metabolism in Rhizopus oryzae for the purpose of increasing lactate yields. Fungal Genet. Biol. 21, 30-39. doi: 10.1006/fgb-i.1996.0952

Mattam, A. J., Kuila, A., Suralikerimath, N., Choudary, N., Rao, P. V., and Velankar, H. R. (2016). Cellulolytic enzyme expression and simultaneous conversion of lignocellulosic sugars into ethanol and xylitol by a new Candida tropicalis strain. Biotechnol. Biofuels 9:157. doi: 10.1186/s13068-0160575-1

McKinlay, J. B., Shachar-Hill, Y., Zeikus, J. G., and Vieille, C. (2007). Determining Actinobacillus succinogenes metabolic pathways and fluxes by NMR and GCMS analysis of 13C-labeled metabolic product isotopomers. Metab. Eng. 9, 177-192. doi: 10.1016/j.ymben.2006.10.006

Morales, P., Rojas, V., Quirós, M., and Gonzalez, R. (2015). The impact of oxygen on the final alcohol content of wine fermented by a mixed starter culture. Appl. Microbiol. Biotechnol. 99, 3993-4003. doi: 10.1007/s00253-0146321-3

Nanssou, P. A. K., Nono, Y. J., and Kapseu, C. (2016). Pretreatment of cassava stems and peelings by thermohydrolysis to enhance hydrolysis yield of cellulose in bioethanol production process. Renewable Energy 97, 252-265. doi: 10.1016/j.renene.2016.05.050

Nielsen, J. (2001). Metabolic engineering. Appl. Microbiol. Biotechnol. 55, 263-283. doi: $10.1007 / \mathrm{s} 002530000511$

Quintero, J. A., Moncada, J., and Cardona, C. A. (2013). Techno-economic analysis of bioethanol production from lignocellulosic residues in Colombia: a process simulation approach. Bioresour. Technol. 139, 300-307. doi: 10.1016/j.biortech.2013.04.048 
Ranganathan, A., Smith, O. P., Youssef, N. H., Struchtemeyer, C. G., Atiyeh, H. K., and Elshahed, M. S. (2017). Utilizing anaerobic fungi for two-stage sugar extraction and biofuel production from lignocellulosic biomass. Front. Microbiol. 5:635. doi: 10.3389/fmicb.-2017.00635

Riascosa, C. A. M., Gomberta, A. K., and Pintoa, J. M. (2005). A global optimi-zation approach for metabolic flux analysis based on labeling balances. Comput. Chem. Eng. 29, 447-458. doi: 10.1016/j.compchemeng.2004. 08.012

Souto, L. R. F., Caliari, M., Soares, M. S., Fiorda, F. A., and Garcia, M. C. (2017). Utilization of residue from cassava starch processing for production of fermentable sugar by enzymatic hydrolysis. Food Sci. Technol. 37, 19-24. doi: 10.1590/16-78-457x.0023

Tomas-Pejo, E., Fermoso, J., Herrador, E., Hernandob, H., Jiménez-Sánchez, S., Ballesteros, M., et al. (2017). Valorization of steam-explo -ded wheat straw through a biorefinery approach: bioethanol and bio-oil coproduction. Fuel. 199, 403-412. doi: 10.1016/j.fuel.2017.03.006
Watanabe, T., Watanabe, I., Yamamoto, M., Ando, A., and Nakamura, T. (2011). A UV-induced mutant of Pichia stipitis with increased ethanol production from xylose and selection of a spontaneous mutant with increased ethanol tolerance. Bioresour. Technol. 102, 1844-1848. doi: 10.1016/j.b-iortech.2010.09.087

Conflict of Interest Statement: The authors declare that the research was conducted in the absence of any commercial or financial relationships that could be construed as a potential conflict of interest.

Copyright (C) 2017 Li, Deng, Yang, Wei, Cheng, Cao, Mu, Luo, Zheng, Jiang and Wu. This is an open-access article distributed under the terms of the Creative Commons Attribution License (CC BY). The use, distribution or reproduction in other forums is permitted, provided the original author(s) or licensor are credited and that the original publication in this journal is cited, in accordance with accepted academic practice. No use, distribution or reproduction is permitted which does not comply with these terms. 